Corresponding Author: Dr. Soghra khani; Associate Professor;

Sexual and Reproductive Health Research center, Nasibeh Nursing and Midwifery School, Vesal Street, Amir Mazandarani Boulevard, Sari, Iran Tel: +981133368918 email:

khanisog343@gmail.com

Received 26 January 2021

Accepted 17 March 2021

Published 31 March 2021

Production and Hosting by Knowledge E

(c) Sedigheh

HasaniMoghadam et al. This article is distributed under the terms of the Creative

Commons Attribution

which permits

unrestricted use and

redistribution provided that the original author and source are credited.

Editor-in-Chief:

Prof. Mohammad A. M. Ibnouf

\section{Communication Patterns and Related Factors among Iranian Couples: A Cross-sectional Study}

\section{Sedigheh HasaniMoghadam¹, Jila Ganji², Hamid Sharif Nia ${ }^{3}$, Mohsen Aarabi ${ }^{4}$, and Soghra Khani ${ }^{5,} 6$}

\author{
${ }^{1}$ Student Research Committee, Nasibeh School of Nursing and Midwifery, Mazandaran University \\ of Medical Sciences, Sari, Iran. \\ ${ }^{2}$ Department of Reproductive Health and Midwifery, Sexual and Reproductive Health Research \\ Center, Mazandaran University of Medical Science, Sari, Iran. \\ ${ }^{3}$ Department of Medical-Surgical Nursing, Amol Faculty of Nursing, Mazandaran University of \\ Medical Sciences, Sari, Iran. \\ ${ }^{4}$ Cardiovascular Research Center, Mazandaran University of Medical Sciences, Sari, Iran. \\ ${ }^{5}$ Department of Reproductive Health and Midwifery, Sexual and Reproductive Health Research \\ Center, Mazandaran University of Medical Sciences, Sari, Iran. \\ ${ }^{6}$ Department of Reproductive Health and Midwifery, Diabetes Research Center, Mazandaran \\ University of Medical Sciences, Sari, Iran.
}

\section{ORCID:}

Soghra Khani: http://orcid.org/0000-0001-6958-8234

\section{Abstract}

Background: Given the effect of various factors on the use of communication patterns by couples, this study aimed to determine the most common communication pattern among couples and related factors in Sari, northern Iran.

Methods: This cross-sectional study was performed on 520 people (260 couples) in Sari. Data were collected using a demographic-fertility factors questionnaire, Enrich couple scale, communication patterns questionnaire, general health questionnaire (GHQ-28), and NEO personality inventory. Data analysis was performed in SPSS version 25 using descriptive and inferential statistics (multiple regression model).

Results: While the mean (standard deviation) age of women included in the study was 34.08 (7.71) years, the mean age of men was 39.13 (9.18) years. The most common communication patterns in both women and men was the mutual constructive communication, whereas the lowest frequent communication pattern was the demand/withdraw communication in both men and women. Marital satisfaction had a significant positive correlation with mutual constructive communication pattern in women and men $(P=0.001)$. In addition, a significant inverse correlation was observed between the number of marriage to date, women's age, and spouses' demand/withdraw communication pattern with mutual constructive communication pattern in women. Also, a significant inverse correlation was observed between flexibility $(P=0.047)$, number of marriages $(P=0.013)$, and the wives' age $(P=0.005)$ with mutual constructive communication pattern in men.

Conclusion: According to the results of the study, it is necessary to recognize the factors related to couples' communication patterns in order to improve the communication patterns so that marital conflicts could be avoided while a more effective communication is established. 


\section{Introduction}

Couple communication patterns play an important role in families. In fact, communication patterns are recognized as a set of communication networks occurring frequently in a family [1-4]. There are three types of couple communication patterns. In mutual constructive communication pattern, couples can easily talk about their issues and solve them without any aggressive behavior. Demand-withdraw pattern, which encompasses two parts including demander husband/withdrawer wife and vice versa. This pattern is in the form of a cycle, where the increase of one leads to the exacerbation of the other, and intensification of the pattern results in more marital issues. In this pattern, a demander spouse is a dependent person while the withdrawer spouse has the fear of becoming dependent. Another pattern is mutual avoidance communication. In this pattern, communication is avoided, minimal, or non-existent [5-9]. Communication patterns can determine the level of marital satisfaction so that $>90 \%$ of disturbed couples consider this problem as their main issue in their relationship [5, 10-12]. Defective communication patterns decrease couples' proper understanding of each other, leading to their failure to support each other, making efforts to meet the needs of each other, and understanding each other's views on conflicting issues. These issues ultimately result in marital issues and dissatisfaction. In contrast, healthy and productive communication patterns are one of the most important factors of marital satisfaction [13-15]. Therefore, modification of couples' communication patterns is a method used in couple therapy to solve marital problems since changing communication patterns is more important, compared to other factors affecting marital conflicts, such as personality traits and socioeconomic status $[5,10,16-18]$.

Several studies have been conducted to evaluate the relationship between couples' communication patterns and various factors such as marital satisfaction and emotional intelligence $[19,20]$. Many studies found that mutual constructive communication pattern was positively correlated with marital satisfaction [20], but some other studies did not support such a link [21, 22].

The need to conduct more research in this area to identify the most common pattern that can lead couples to more emotional and orderly relationships is felt in every society. In the present study, the basis of the work is couples' communication pattern, which is followed to determine the factors positively and negatively affecting this issue so that the necessary suggestions could be made for consolidating the family foundation. To the best of our knowledge, there is no comprehensive study evaluating couples' communication patterns and related factors in Iran, especially in Mazandaran Province. 
Moreover, most studies have focused on the evaluation of patterns of family communication [23]. Considering the aforementioned issue, this study aimed to determine the most common couples' communication pattern and related factors in Sari, Iran. It is hoped that effective steps could be taken toward solving couples' marital conflicts by recognizing these patterns.

\section{Materials and Methods}

This cross-sectional research was performed on couples in Sari, north of Iran in 2018. The inclusion criteria of the study were being a couple residing in Sari, educational level of elementary fifth and above, living with the spouse, and being married for a minimum of one year. The exclusion criterion was the unwillingness of one or both spouses to participate in the study. In total, 27 households were randomly determined as cluster heads by the health center statistics unit using the random number table. The sample size was determined by selecting 10 samples for each factor, which led to the selection of 350 people (175 couples). Since subjects were selected by cluster sampling and the impact factor was 1.5 , a total of 524 people ( 262 couples) were selected.

However, two couples were removed from the research due to incomplete questionnaires, which led to the entrance of 10 families in each cluster (260 couples). Notably, 27 students were trained in a 3-hr educational session to conduct the research inquiry. The inquiry sessions took 30-45 min. After receiving the address of cluster heads, the interviewers referred to the addresses as two-member teams every day. In case of the absence of households or their unwillingness to participate in the study, inquiries were conducted with other households. Interviews were conducted in an apartment. Of note, interviewers verbally explained the questionnaire to each couple. In addition, research objectives were explained prior to the study and the subjects were ensured of the confidentiality terms regarding their personal information. In addition, they were allowed to withdraw from the research at any time. Data were collected using the following tools:

\section{Demographic-fertility factors questionnaire}

This questionnaire comprised of two sections of demographic characteristics and fertility-related information such as type of contraceptive method; history, type, and cause of infertility; children from a previous marriage; menstrual cycle regularity; duration of menstrual cycle; current pregnancy; number of children; currently living with the spouse; and children's gender. 


\section{Enrich couple scale (ECS)}

The 35-item version of the ECS scale was used. The validity and reliability of this questionnaire have previously been confirmed in Iran $[24,25]$.

\section{The communication patterns questionnaire (Christensen and Salavi)}

This was a 35-item questionnaire, validity and reliability of which have been confirmed in Iran [26].

\section{General health questionnaire (GHQ-28)}

The GHQ-28 is a 28-item questionnaire, the validity and reliability of which have previously been confirmed in Iran [27].

\section{NEO personality inventory}

This was a 60-item questionnaire. The validity and reliability of this questionnaire have been confirmed in Iran [28].

\subsection{Statistical analysis}

Data were analyzed by SPSS version 25 using a skewness-kurtosis test (to assess the normal distribution of the data), as well as descriptive (frequency, mean, and standard deviation [SD]) and inferential (linear and multiple regressions) statistics. First, the relationship between factors related to the communication patterns was evaluated applying the univariate regression. Ultimately, the significant factors that had linear relations were entered into the multiple regression model to determine the predictive variables of couples' communication patterns. Moreover, the cutoff point of the patterns was obtained based on the estimation of half the difference between maximum and minimum scores in order to determine the frequency of couples' communication patterns, followed by developing a dichotomous variable. In this context, the scores obtained from the minimum possible score of the questionnaire to the cut-off point were coded 0 while the scores above that level were scored 1. In the end, the frequency and related factors of these dichotomous variables were estimated.

\section{Results}

According to the results of the study, the mean (SD) age of women was 34.08 (7.71) years and that of men was 39.13 (9.18) years. The majority of women were housewives (69.6\%) while the majority of men were employees (43.8\%). In terms of the level of education, 
most men and women had a degree between diploma and BSc (68.5\% and $72.3 \%$, respectively) (Table 1).

TABLE 1: Demographic characteristics of subjects.

\begin{tabular}{|c|c|}
\hline Variables & Category \\
\hline \multirow{3}{*}{$\begin{array}{l}\text { Level of } \\
\text { education } N^{*}(\%)\end{array}$} & Below diploma \\
\hline & Diploma to BSC \\
\hline & Above BSc \\
\hline \multirow[t]{4}{*}{$\begin{array}{l}\text { Level of } \\
\text { occupation N (\%) }\end{array}$} & $\begin{array}{l}\text { Unemployed/ } \\
\text { housewife }\end{array}$ \\
\hline & Employee \\
\hline & Worker \\
\hline & Other \\
\hline Age (yr) & \\
\hline $\mathrm{M}^{* *}\left(\mathrm{SD}^{* * *}\right)$ & \\
\hline $\begin{array}{l}\text { Age at marriage } \\
\text { in female (yr) }\end{array}$ & \\
\hline M (SD) & \\
\hline $\begin{array}{l}\text { Duration of } \\
\text { marriage (yr) }\end{array}$ & \\
\hline$M(S D)$ & \\
\hline $\begin{array}{l}\text { Duration of } \\
\text { relationship with } \\
\text { the spouse before } \\
\text { marriage (month); } \\
\text { M (SD) }\end{array}$ & \\
\hline
\end{tabular}

\begin{tabular}{|c|}
\hline Male \\
\hline $40(15.4)$ \\
\hline $188(72.3)$ \\
\hline $32(12.8)$ \\
\hline $7(2.7)$ \\
\hline $114(43.8)$ \\
\hline 38 (14.6) \\
\hline $101(38.9)$ \\
\hline Minimum \\
\hline Maximum \\
\hline $22.02(4.58)$ \\
\hline 11.86 (8.54) \\
\hline $22.74(31.53)$ \\
\hline
\end{tabular}
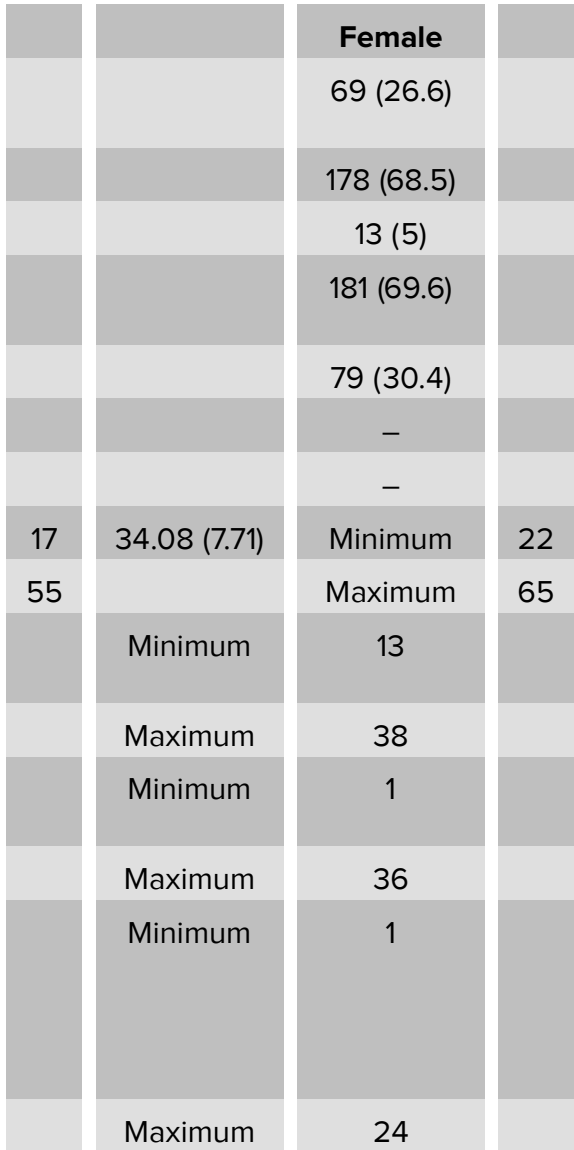

${ }^{*}$ Number; ${ }^{* *}$ Mean; ${ }^{* * *}$ Standard Deviation

Frequency of communication patterns and the related factors are presented in Tables 2 to 4 .

TABLE 2: Frequency distribution of couples' communication patterns.

Communication pattern
Demand/withdraw
communication

\begin{tabular}{|c|}
\hline Sex \\
\hline Female \\
\hline Male \\
\hline Female \\
\hline Male \\
\hline Female \\
\hline Male
\end{tabular}

\begin{tabular}{|c|c|}
\hline $\mathbf{N}(\%)$ & Minimum \\
\hline $89(34.2)$ & 6 \\
\hline $101(38.8)$ & \\
\hline $230(88.5)$ & -23 \\
\hline $227(87.3)$ & \\
\hline $130(50)$ & 3 \\
\hline $105(40.4)$ & \\
\hline
\end{tabular}

\begin{tabular}{|c|}
\hline Maximum \\
\hline 47 \\
\hline 23 \\
\hline 27 \\
\hline
\end{tabular}

\begin{tabular}{|c|}
\hline Cut-off point \\
\hline 20.5 \\
\hline 23 \\
\hline 12 \\
\hline
\end{tabular}


TABLE 3: Regression of factors related to Mutual constructive communication pattern in women

\begin{tabular}{|c|c|c|c|c|c|c|c|c|c|}
\hline \multirow{2}{*}{$\begin{array}{l}\text { Type of } \\
\text { communica- } \\
\text { tion }\end{array}$} & \multirow{2}{*}{$\begin{array}{l}\text { Predictive } \\
\text { variable }\end{array}$} & \multicolumn{4}{|c|}{ Non-modified (simple) } & \multicolumn{4}{|c|}{ Modified (multiple) } \\
\hline & & B & $\beta$ & $P$-value & $\mathrm{Cl}_{95 \%}$ & B & $\beta$ & $P$-value & $\mathrm{Cl}_{95 \%}$ \\
\hline \multirow{4}{*}{$\begin{array}{l}\text { Mutual } \\
\text { constructive } \\
\text { communica- } \\
\text { tion } \\
\text { pattern }\end{array}$} & $\begin{array}{l}\text { Marital } \\
\text { satisfaction }\end{array}$ & 0.22 & 0.384 & 0.001 & $\begin{array}{l}0.174 \\
0.265\end{array}$ & 0.223 & 0.387 & 0.001 & $\begin{array}{l}0.156 \\
0.291\end{array}$ \\
\hline & $\begin{array}{l}\text { Number of } \\
\text { marriages to } \\
\text { date }\end{array}$ & -6.197 & -0.146 & 0.019 & $\begin{array}{l}-11.357 \\
-1.038\end{array}$ & -7.18 & -0.123 & 0.013 & $\begin{array}{c}-12.844 \\
-1.515\end{array}$ \\
\hline & $\begin{array}{l}\text { Women's } \\
\text { age }\end{array}$ & -0.154 & -0.143 & 0.021 & $\begin{array}{l}-0.284 \\
-0.024\end{array}$ & -0.166 & -0.134 & 0.036 & $\begin{array}{l}-0.331 \\
0.00\end{array}$ \\
\hline & $\begin{array}{l}\text { Male } \\
\text { demand/ } \\
\text { withdraw } \\
\text { communica- } \\
\text { tion } \\
\text { pattern }\end{array}$ & -0.126 & 0.159 & 0.001 & $\begin{array}{l}-0.194 \\
0.059\end{array}$ & -0.101 & -0.122 & 0.019 & $\begin{array}{l}-0.185 \\
-0.017\end{array}$ \\
\hline
\end{tabular}

TABLE 4: Regression of factors related to mutual constructive communication pattern in men.

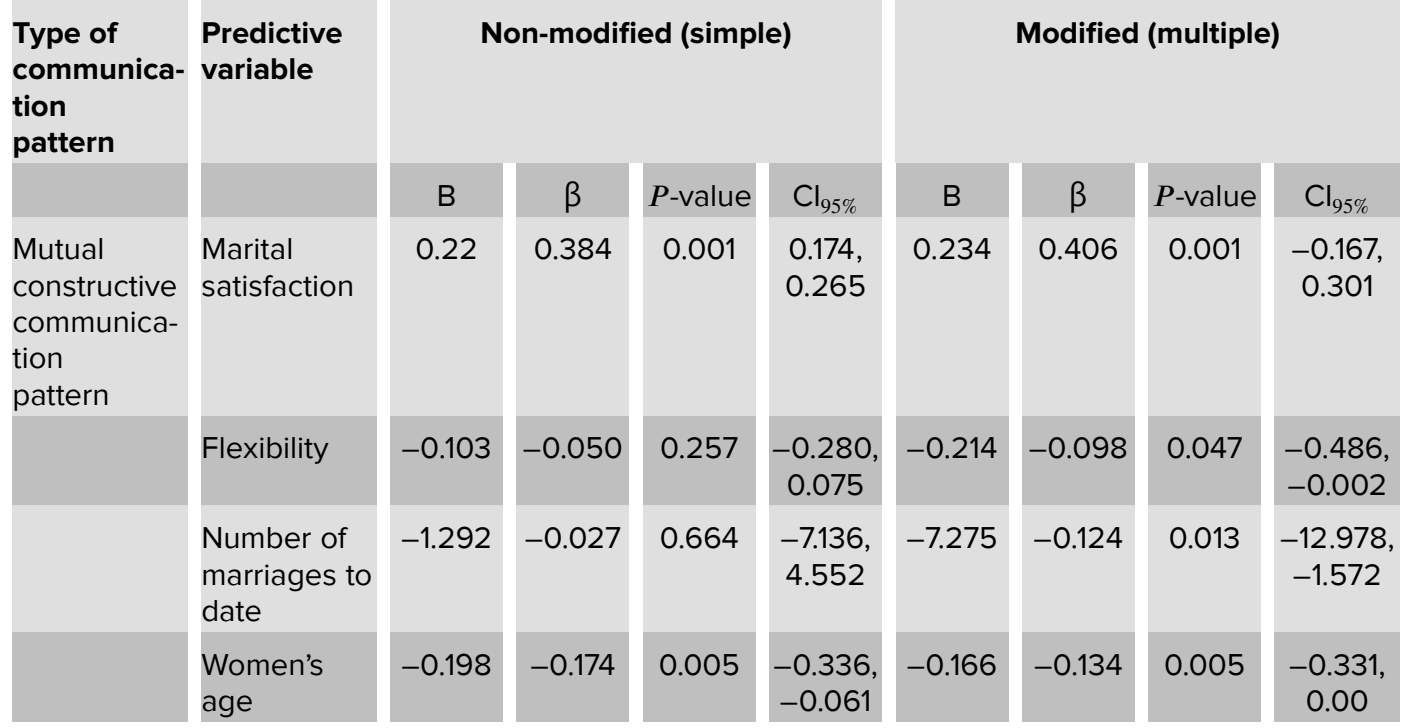

\section{Discussion}

The couples' communication pattern is a process during which the wife and husband interact with each other verbally and non-verbally. Researchers believe that over $90 \%$ of dissatisfied couples report an inability to communicate as a major issue in their lives. Suitable communication patterns significantly affect couples' current life, whereas improper communication can result in the separation of couples. Changing communication patterns are the most prominent ways to deal with marital maladjustments and 
couple therapies [29]. According to the results of the present research, the highest and lowest frequencies were related to mutual constructive and demand/withdraw communication patterns, respectively. A review of the literature revealed a lack of a research to evaluate the distribution of couples' communication patterns. In this context, it could be expressed that spouses who use the mutual constructive pattern more in their marital relationship avoid destructive behaviors more and make efforts to establish a healthy relationship. In addition, they feel that they understand each other, express their feelings appropriately, suggest a solution to the communication problem, and negotiate with each other, which ultimately results in more satisfaction with their marital life [29, 30]. Furthermore, using the demand/withdraw communication pattern by couples could lead to decreased marital satisfaction (especially when there is a demander wife and a withdrawer husband) and might predict divorce. In this respect, the more the use of demand/withdraw communication pattern, the lower the level of marital compatibility [10].

Our findings revealed a significant, negative relationship between women's age and mutual constructive communication pattern (in men and women), which is consistent with the results of Khodakarami et al. [31] and Bakhshi et al. [32]. On the other hand, our findings were inconsistent with the results of Vaijayanthimala et al. [33] and Karny et al. [34]. The results obtained by Bakhshi et al. [32] and Khodakarami et al. [31] demonstrated that the level of marital satisfaction decreased by the increase in women's age. This finding can be justified by the fact that as a woman gets older, she becomes more mature and aware of her marital status, which in turn reduces marital conflicts and problems. In contrast, marriage at a young age can lead to numerous problems and consequently reduced marital satisfaction due to a lack of physical, mental, and emotional preparedness. It may be argued that since individuals have not yet attained the mental, emotional, cultural, social, economic growth, they have not gained many of the skills required to lead a successful life and lack the necessary skills to play the role of spouse, which often leads to many conflicts and incompatibilities. The necessity of achieving economic growth and job stability for men with regard to their responsibilities in providing family finances and housing in marriage and finishing the military service results in the preparedness of men for marriage at an age higher than women, which itself could decrease problems and increase marital satisfaction.

According to the results of the present study, there was an inverse correlation between the number of marriages and mutual constructive communication patterns (in men and women). Based on these findings, more marriages can lead to more marital strife. Other studies have shown that the duration of marriage could have a different 
effect on marital intimacy. Furthermore, Kardan-Souraki et al. marked a negative and significant correlation between marital intimacy and the duration of the marriage. In other words, the couple's intimacy level decreased by the increased duration of marriage [35]. Our findings also demonstrated a negative association between flexibility personality traits and mutual constructive communication patterns only in men. This could be justified by the fact that due to inherent traits and variety-driven personality, as well as issues related to financial and social problems, financial costs, inflation in today's society of Iran in the past few years, and tolerating additional financial pressure and mental tensions, men might practice inappropriate behaviors that could lead to marital conflicts and decrease flexibility in the relationship with the spouse and dealing with family problems $[36,37]$.

Our study indicate an inverse correlation between demand/withdraw communication pattern in men and mutual constructive communication pattern in women. In a research by Gottman et al., it was reported that the demand/withdraw communication pattern (especially when there is a demander wife and a withdrawer husband) led to decreased marital satisfaction and increased possibility of divorce [30]. In a study aimed to evaluate the relationship between the demand/withdraw communication pattern and marital compatibility, it was concluded that the more the use of the demand/withdraw communication pattern by couples, the lower the level of marital compatibility [38]. While previous studies have shown a relationship between this pattern and marital satisfaction and compatibility, most of them have suggested that the nature of this model is complex and how it is affected is not yet fully understood. This complexity and lack of certainty of the type of relationship can be justified by the fact that the association between marital communication patterns and marital satisfaction might depend on the couples' beliefs about marriage. Therefore, given the role of this pattern in the prediction of important marriage consequences (e.g., marital satisfaction and divorce) [30], it is recommended that efforts be dedicated to a better and more accurate understanding of the relationship in future studies.

According to the results of the current study, there was a positive relationship between marital satisfaction and mutual constructive communication pattern in men and women, which is in line with the results of other studies [39, 40]. In this regard, it could be pointed out that couples who use mutual constructive communication patterns more in their marital relation avoid destructive behaviors and make efforts to maintain a healthy relationship. In addition, they feel that they understand each other, can properly express their feelings, find solutions for communication problems and negotiate, which ultimately increases their marital satisfaction. 
The lack of the presence of men at the time of interviews, which was controlled by visiting the home of the participants by prior appointment is a limitation of our study. All questionnaires were checked for completeness at the time of delivery and the parts left incomplete were explained to the couples again. In case of the presence of spouse, the questionnaires would be completed at the same time; otherwise, interviewers would refer to the participants to complete the questionnaires at another time. Some of the strengths of the present study included cluster sampling, referral of interviewers to the house of the participants in the presence of the man of the house, and the completeness of the questionnaires used.

\section{Conclusion}

According to the results of the study, the most common communication pattern in both women and men was the mutual constructive communication pattern. Therefore, it is necessary to recognize the factors related to mutual constructive communication patterns in couples so that marital conflicts could be avoided while a more effective communication is established.

\section{Acknowledgments}

The authors acknowledge the financial support of the deputy of research and technology of Mazandaran University of Medical Sciences, Sari, Iran.

\section{Ethical considerations}

Subjects were selected by cluster sampling after approval from the vice-chancellor for research and the ethics committee of the Mazandaran University of Medical Sciences. An introduction letter was obtained from the vice-chancellor for research and presented to the relevant centers. All subjects gave a written informed consent prior to participating in the study.

\section{Competing interests}

The authors have no conflicts of interest to declare for this study. 


\section{Availability of data and material}

All relevant data and methodological detail pertaining to this study are available to any interested researchers upon reasonable request to corresponding author.

\section{Funding}

This study has been financially supported by the Deputy of Research and Technology, Mazandaran University of Medical Sciences, Sari, Iran.

\section{Author's' contributions}

SHM and SK conceived and designed the study, conducted research, provided research materials, and collected and organized data. SK supervised the research process. HSN and MA analyzed and interpreted data. SHM, SK, and JG wrote the initial and final draft of the article and provided logistic support. All authors have critically reviewed and approved the final draft and are responsible for the content and similarity index of the manuscript.

\section{References}

[1] Lavner, J. A., Barton, A. W., and Beach, S. R. (2019). Improving couples' relationship functioning leads to improved coparenting: a randomized controlled trial with rural African American couples. Behavior Therapy, vol. 50, no. 6, pp. 1016-1029.

[2] Lavner, J. A., Karney, B. R., and Bradbury, T. N. (2016). Does couples' communication predict marital satisfaction, or does marital satisfaction predict communication? Journal of Marriage and Family, vol. 78, no. 3, pp. 680-694.

[3] Narimani, M., Pouresmali, A., Mikaeili, N., et al. (2015). The mediating role of couple communication patterns in the relationship between enduring vulnerabilities and marital burnout in the divorce- seeking couples. Journal of Family Psychology, vol. 2, no. 2, pp. 51-66.

[4] Mitchell, J. W. and Gamarel, K. E. (2018). Constructive communication patterns and associated factors among male couples. Journal of Couple \& Relationship Therapy, vol. 17, no. 2, pp. 79-96.

[5] Chi, P., Epstein, N. B., Fang, X., et al. (2013). Similarity of relationship standards, couple communication patterns, and marital satisfaction among Chinese couples. 
Journal of Family Psychology, vol. 27, no. 5, pp. 806-816.

[6] Gilbert, R. L., Murphy, N. A., and Ávalos, M. C. (2011). Communication patterns and satisfaction levels in three-dimensional versus real-life intimate relationships. Cyberpsychology, Behavior, and Social Networking, vol. 14, no. 10, pp. 585-589.

[7] Overall, N. C. and McNulty, J. K. (2017). What type of communication during conflict is beneficial for intimate relationships? Current Opinion in Psychology, vol. 13, pp. $1-5$.

[8] Yoo, H., Bartle-Haring, S., Day, R. D., et al. (2014). Couple communication, emotional and sexual intimacy, and relationship satisfaction. Journal of Sex \& Marital Therapy, vol. 40, no. 4, pp. 275-293.

[9] Crenshaw, A. O., Christensen, A., Baucom, D. H., et al. (2017). Revised scoring and improved reliability for the Communication Patterns Questionnaire. Psychological Assessment, vol. 29, no. 7, pp. 913-925.

[10] Falconier, M. K. and Epstein, N. B. (2011). Female-demand/male-withdraw communication in Argentinian couples: a mediating factor between economic strain and relationship distress. Personal Relationships, vol. 18, no. 4, pp. 586-603.

[11] Litzinger, S. and Gordon, K. C. (2005). Exploring relationships among communication, sexual satisfaction, and marital satisfaction. Journal of Sex \& Marital Therapy, vol. 31, no. 5, pp. 409-424.

[12] Jones, A. C., Robinson, W. D., and Seedall, R. B. (2018). The role of sexual communication in couples' sexual outcomes: a dyadic path analysis. Journal of Marital and Family Therapy, vol. 44, no. 4, pp. 606-623.

[13] Denton, W. H. and Burleson, B. R. (2007). The initiator style questionnaire: a scale to assess initiator tendency in couples. Personal Relationships, vol. 14, no. 2, pp. 245-268.

[14] Zaheri, F., Dolatian, M., Shariati, M., et al. (2016). Effective factors in marital satisfaction in perspective of Iranian women and men: a systematic review. Electronic Physician, vol. 8, no. 12, pp. 3369-3377.

[15] Overall, N. C., Fletcher, G. J., Simpson, J. A., et al. (2009). Regulating partners in intimate relationships: the costs and benefits of different communication strategies. Journal of Personality and Social Psychology, vol. 96, no. 3, pp. 620-639.

[16] Baucom, K. J., Sevier, M., Eldridge, K. A., et al. (2011). Observed communication in couples two years after integrative and traditional behavioral couple therapy: outcome and link with five-year follow-up. Journal of Consulting and Clinical Psychology, vol. 79, no. 5, pp. 565-576. 
[17] Schofield, M. J., Mumford, N., Jurkovic, D., et al. (2012). Short and long-term effectiveness of couple counselling: a study protocol. BMC Public Health, vol. 12, p. 735.

[18] Christensen, A. and Doss, B. D. (2017). Integrative behavioral couple therapy. Current Opinion in Psychology, vol. 13, pp. 111-114.

[19] Alonso Ferres, M., Valor Segura, I., and Expósito Jiménez, F. (2019). Couple conflictfacing responses from a gender perspective: emotional intelligence as a differential pattern. Psychiatry International, vol. 28, no. 3, pp. 147-156.

[20] Han, K., Weed, N. C., and Butcher, J. N. (2003). Dyadic agreement on the MMPI-2. Personality and Individual Differences, vol. 35, no. 3, pp. 603-615.

[21] Gattis, K. S., Berns, S., Simpson, L. E., et al. (2004). Birds of a feather or strange birds? Ties among personality dimensions, similarity, and marital quality. Journal of Family Psychology, vol. 18, no. 4, pp. 564-574.

[22] Watson, D., Klohnen, E. C., Casillas, A., et al. (2004). Match makers and deal breakers: analyses of assortative.mating in newlywed couples. Journal of Personality, vol. 72, no. 5, pp. 1029-1068.

[23] Dorrance Hall, E., Ma, M., Azimova, D., et al. (2020). The mediating role of family and cultural food beliefs on the relationship between family communication patterns and diet and health issues across racial/ethnic groups. Health Communication, vol. 9, pp. 1-13.

[24] Daneshpour, M., Asoodeh, M. H., Khalili, S., et al. (2011). Self described happy couples and factors of successful marriage in Iran. Journal of Systemic Therapies, vol. 30, no. 2, pp. 43-64.

[25] Azimi Lolati, H., Hosseini, S. H., Khalilian, A., et al. (2005). Postpartum depression in clients at health care centers in Sari. Iranian Journal of Psychiatry and Clinical Psychology, vol. 11, no. 1, pp. 31-42.

[26] Ebadatpur, B. (2000). Validation of Communication Patterns Questionnaire (Master's Thesis). Faculty of Psychology and Educational Sciences, Teacher Training University of Tehran, Iran.

[27] Nazifi, M., Mokarami, H., Akbaritabar, A., et al. (2014). Reliability, Validity and Factor Structure of the Persian Translation of General Health Questionnire (GHQ-28) in Hospitals of Kerman University of Medical Sciences. Journal of Fasa University of Medical Sciences, vol. 3, no. 4, pp. 336-342.

[28] Garussi Farshi, M. T., Mehriar, A. H., and Ghazi tabatabaee, S. M. (2001). Application of New Neo Personality Test (NEO) and Analysis of its Characteristics and Factor 
Structure among Iranian University Students. Journal of Humanities, vol. 11, no. 39, pp. 173-198.

[29] Papp, L. M., Goeke-Morey, M. C., and Cummings, E. M. (2007). Linkages between spouses psychological distress and marital conflict in the home. Journal of Family Psychology, vol. 21, no. 3, pp. 533-537.

[30] Gottman, J. M. and Notarius, C. I. (2000). Decade review: observing marital interaction. Journal of Marriage and Family, vol. 62, no. 4, pp. 927-947.

[31] Khodakarami, B., Masoomi, S. Z., and Asadi, R. (2017). The status and marital satisfaction factors in nulliparous pregnant females attending clinics in Asadabad City during years 2015 and 2016. Avicenna Journal of Nursing and Midwifery Care, vol. 25, no. 1, pp. 52-59.

[32] Bakhshi, H., Asadpour, M., and Khodadadizadeh, A. (2007). Correlation between marital satisfaction and depression among couples in Rafsanjan. Journal of Qazvin University of Medical Science, vol. 11, no. 2, pp. 37-43.

[33] Vaijayanthimala, K., Kumari, K. B., and Panda, B. (2004). Socio-economic heterogomy and marital satisfaction. Human Ecology, vol. 15, no. 1, pp. 9-11.

[34] Karney, B. R. and Bradbury, T. N. (2005). Contextual influences on marriage: Implications for policy and intervention. Current Directions in Psychological Science, vol. 14, no. 4, pp. 171-174.

[35] Kardan-Souraki, M., Asadpour, I., Mohammadpour, R. A., et al. (2016). A review of marital intimacy-enhancing interventions among married individuals. Global Journal of Health Science, vol. 8, no. 8, p. 53109.

[36] Burgess, S., Propper, C., and Aassve, A. (2003). The role of income in marriage and divorce transitions among young Americans. Journal of Population Economics, vol. 16, pp. 455-475.

[37] Nunley, J. M. and Seals, A. (2010). The effects of household income volatility on divorce. American Journal of Economics and Sociology, vol. 69, no. 3, pp. 9831010.

[38] Delaney, A. L. and Sharabi, L. L. (2020). Relational uncertainty and interference from a partner as predictors of demand/withdraw in couples with depressive symptoms. Western Journal of Communication, vol. 84, no. 1, pp. 58-78.

[39] Gottman, J. M. N. C. (2002). Marital in 20th century and research and for 21st century. Family Process, vol. 41, no. 2, pp. 159-197.

[40] Plooy, K. D. and Beer, R. D. (2018). Effective interactions: communication and high levels of marital satisfaction. Journal of Psychology in Africa, vol. 28, no. 2, pp. 161-167. 